\title{
Biblioteca do Paiaiá: território de memórias e identidades para a formação de leitores
}

Paiaiá Library: territory of memories and identities for the formation of readers

\section{Mírian Sumica Carneiro Reis*}

Universidade da Integração Internacional da Lusofonia Afro-brasileira, campus dos Malês

\section{Maria Helena da Rocha Besnosik*}

Universidade Estadual de Feira de Santana

\section{Claudio Cledson Novaes*}

Universidade Estadual de Feira de Santana

\footnotetext{
* Professora de Teoria da Literatura da Universidade da Integração Internacional da Lusofonia Afro-brasileira, no campus dos Malês, Bahia, doutora em Ciência da Literatura pela UFRJ. Coordena o Literarte - Grupo de Estudos em Literatura e Outras Linguagens. E-mail: miriansumica@unilab.edu.br.

** Professora titular da Universidade Estadual de Feira de Santana, doutora em Educação pela USP. E-mail: maria.besnosik@gmail.com.

** Professor pleno da Universidade Estadual de Feira de Santana, doutor em Ciências da Comunicação pela USP, coordenador do NELCI - Núcleo de Estudos em Literatura e Cinema. E-mail: ccnovaes.uefs@gmail.com.
} 
Resumo: Este artigo apresenta reflexões sobre experiências de leitura empreendidas para e sobre a formação de leitores, problematizando os dispositivos da leitura a partir da configuração identitária da Associação Biblioteca Comunitária Maria das Neves Prado, a Biblioteca do Paiaiá, localizada no interior do semiárido baiano. Apresenta-se, aqui, a importância de iniciativas de democratização do acesso à leitura como instrumento de cidadania e inclusão social, a partir do sentimento de identidade inspirada no território de memórias e afetos que é a "maior biblioteca comunitária rural do mundo".

Palavras-chave: Leitura; Biblioteca; Comunidade; Identidades; Memórias.

Abstract: This article presents reflections about reading experiences undertaken for and about the formation of readers, problematizing reading devices based on the identity configuration of the Maria das Neves Prado Community Library Association, the Paiaiá Library, located in the interior of the Bahian semi - arid region. Here, the importance of initiatives to democratize access to reading as an instrument of citizenship and social inclusion is presented, based on the feeling of identity inspired by the territory of memories and affections that is the "largest rural community library in the world".

Keywords: Reading; Library; Community; Identities; Memories.

Recebido em 20 de dezembro de 2018

Aprovado em 25 de maio de 2019

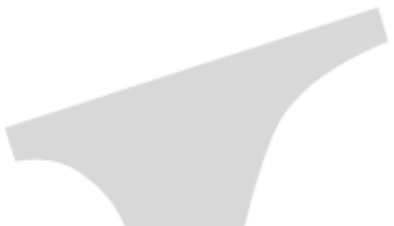

REIS, Mírian Sumica Carneiro; BESNOSIK, Maria Helena da Rocha; NOVAES, Claudio Cledson. Biblioteca do Paiaiá: território de memórias e identidades para a formação de leitores. Légua \& Meia, Brasil, n. 9, v. 1, p. 146-158, 2019. 
Para Geraldo Moreira Prado, nosso Alagoinha.

\section{Era uma vez...}

...Um jovem sertanejo, que saiu das distantes terras de São José do Paiaiá, no município de Nova Soure - BA, no último pau-de-arara, para tentar a vida no Sudeste. Destino: o mesmo de seus antecessores - o sonho brasileiro do self made man encarnado na famosa São Paulo. Eram os anos de 1960, e entre os serviços de faxineiro, porteiro, contínuo de escritório e vendedor de enciclopédia, Geraldo Moreira Prado fez supletivo, concluiu o colegial e tentou o vestibular para Chinês na USP. Vocação para o Comunismo? Ainda não... Como ele mesmo gosta de contar, foi senso de oportunidade: era o primeiro vestibular para aquele curso e havia sobra de vagas. Depois de matriculado, e das primeiras tentativas frustradas de aprender mandarim, Geraldo entendeu que seu lugar era outro, e transferiu sua matrícula para o curso de História. Morador do CRUSP (Centro de Residência Universitária da USP), recebeu novos batismos: a alcunha de Alagoinha, o comunismo, as aulas com Antonio Candido e Florestan Fernandes, a militância contra a ditatura, a prisão e a tortura no DOPS, a paixão pelos livros.

Geraldo concluiu a graduação em História, fez Mestrado e Doutorado, tornou-se professor da Universidade Federal do Rio de Janeiro (UFRJ), pesquisador de produtividade do CNPq, professor do Instituto Brasileiro de Informação, Ciência e Tecnologia (IBICT). Mas o fato de ter contrariado o destino do migrante nordestino, já poderia indicar meritocracia, mas esse ainda não é seu principal feito. Seu maior projeto é coletivo e colaborativo, como seu espírito de sertanejo.

No ano de 2001, Geraldo encontrou um modo ainda pouco usual para contribuir com o desenvolvimento da sua região de origem: professor de ofício e vocação, transferiu sua biblioteca pessoal para o povoado de São José do Paiaiá, onde nasceu, criando aquela que ficaria conhecida como a "maior biblioteca rural do mundo" (cf. REIS, In NOVAES et al, 2016, p. 229-230).

O título, grandiloquente, reflete o pioneirismo da ação de Geraldo e o movimento que ele desencadeou na comunidade onde, ainda hoje, os jovens que querem estudar precisam migrar para cidades maiores. A Associação Biblioteca Comunitária Maria das Neves Prado nasceu da combinação entre juventude e experiência, necessidade e vontade: um grupo de jovens do Paiaiá, secundaristas à época, saiu pedindo aos vizinhos livros para formar uma biblioteca, para facilitar os estudos numa época em que computador e internet ainda não eram instrumentos democratizados. Um desses jovens, José Arivaldo Prado, sobrinho de Geraldo, sabedor do gosto do tio por livros, resolveu pedir alguns exemplares. O resultado: um caminhão fretado, vindo do Rio de Janeiro para a Bahia, com milhares de títulos de diversas áreas do conhecimento. $\mathrm{O}$ acervo possui, atualmente, mais de 100 mil títulos, entre livros, periódicos, jornais e filmes.

A Associação Biblioteca Maria das Neves Prado, mais conhecida como Biblioteca do Paiaiá, já nasceu grande e comunitária. Seu nome presta homenagem à primeira professora do povoado, Dona Maria das Neves Prado, que enfrentou muitos desafios para cumprir aquilo que considerava sua missão de professora leiga - alfabetizar as crianças da região. Em 2004, a biblioteca foi oficialmente registrada como Organização da Sociedade Civil de Interesse Público (OSCIP) e vem promovendo mudanças gradativas no comportamento dos estudantes de toda a circunvizinhança do povoado do Paiaiá. As histórias contadas por José Arivaldo Prado, o Vadinho, sobrinho de Geraldo, primeiro 
presidente da biblioteca e até hoje seu principal coordenador, são estimulantes para que novos parceiros se agreguem a esse projeto e promovam a sua divulgação.

Como não se emocionar com a história do pequeno produtor rural que, mesmo analfabeto, é um sócio assíduo da biblioteca, onde lê nas figuras dos folhetos da EMBRAPA os conhecimentos acadêmicos que ratificam ou orientam seus conhecimentos telúricos sobre as plantas e bichos do seu roçado? Como não se comprometer com o futuro dos pequeninos que vão fazer a lição de casa no espaço de leitura da biblioteca, minúsculo fisicamente, mas imensurável nas histórias e estórias das páginas impressas e das imaginações dessas crianças?

Talvez as condições de vida da população de São José do Paiaiá não tenham mudado com a intensidade necessária nesses 14 anos de existência formal da Biblioteca do Paiaiá, mas o seu fortalecimento, apesar de todas as dificuldades (financeiras, técnicas e de instalação), graças ao apoio da comunidade e à perseverança de Geraldo e dos membros do Conselho da Associação Biblioteca Comunitária Maria das Neves Prado, reflete a importância de um movimento em favor de novas perspectivas para a difusão do conhecimento e do fomento à leitura.

\section{Projetos que inspiram ações}

A Associação Biblioteca Comunitária Maria das Neves Prado promove, desde sua fundação, um conjunto de ações e eventos de inclusão social a partir da leitura. Já concorreu a editais nacionais e internacionais, públicos e privados, e hoje acumula as funções de Ponto de Leitura e Ponto Digital. Nas suas práticas, o fomento à leitura se destaca, considerando a lição de Antonio Candido no ensaio "O direito à literatura", ao apontar a importância da literatura como conjunto de impulsos, crenças, sentimentos, normas e valores sociais:

Por isso é que nas nossas sociedades a literatura tem sido um instrumento poderoso de instrução e educação, entrando nos currículos, sendo proposta a cada um como equipamento intelectual e afetivo. Os valores que a sociedade preconiza, ou os que considera prejudiciais, estão sempre nas diversas manifestações da ficção, da poesia e da ação dramática. A literatura confirma e nega, propõe e denuncia, apoia e combate, fortalecendo a possibilidade de vivermos dialeticamente os problemas. Por isso é indispensável tanto a literatura sancionada como a literatura proscrita; a que os poderes sugerem e as que nascem dos movimentos de negação do estado de coisas predominante (CANDIDO, 2004, p.175).

Seguindo o pressuposto de que toda leitura é necessária, porque libertária, o fato de a Biblioteca do Paiaiá ser comunitária amplia seu alcance. Diferentemente da biblioteca pública, fundada e mantida por gestões municipais ou estaduais, e da universitária, cuja instância mantenedora é a universidade, a biblioteca comunitária, conforme Elisa Machado, apresenta características específicas que potencializam suas ações, em seu território, como:

1. a forma de constituição: são bibliotecas criadas efetivamente pela e não para a comunidade, como resultado de uma ação cultural. 2. a perspectiva comum do grupo em torno do combate à exclusão informacional como forma de luta pela igualdade e justiça social. 3. o processo participativo gerando articulação local e forte vínculo com a comunidade. 4. a referência espacial: estão, em geral, localizadas em regiões 
periféricas. 5. o fato de não serem instituições governamentais, ou com vinculação direta aos Municípios, Estados ou Federação (MACHADO, 2009, p. 89).

A Biblioteca do Paiaiá integra, em seu projeto-ação, os desafios de promover o fomento à leitura fazendo a inversão da rota pela busca do conhecimento. É um trabalho pioneiro no território do semiárido baiano, onde está localizada, e tem estimulado à pesquisa sobre suas características, os indicadores de educação no território, o papel da leitura como instrumento de cidadania.

Um dos exemplos de pesquisa estimulada pelo engajamento que a Biblioteca do Paiaiá estimula foi realizada por Mírian Sumica Carneiro Reis, durante estágio pósdoutoral, intitulada Círculo de Multi-leituras em Literatura e Cinema: reflexões sobre memória e identidade na "maior biblioteca rural do mundo". O projeto inicial foi apresentado ao Programa de Pós-graduação em Educação da Universidade Estadual de Feira de Santana (PPGE - UEFS) sob a anuência e supervisão da professora doutora Maria Helena da Rocha Besnosik em abril de 2014. Após aprovação do colegiado daquele Programa, o projeto recebeu financiamento do Programa Nacional de Pós-Doutorado da CAPES até maio de 2015, quando se encerraram as atividades, sem pedido de renovação ou prorrogação.

O objetivo geral do projeto foi, a partir do pressuposto de que educação se faz por meio de suportes múltiplos, propor o diálogo entre literatura e cinema como suporte metodológico eficiente para a reflexão sobre imagens identitárias na formação de leitores, tomando como estudo de caso as ações de educação e cidadania promovidas pela Biblioteca Comunitária Maria das Neves Prado, no povoado de São José do Paiaiá, município de Nova Soure - BA.

A proposta inicial previa a pesquisa em três etapas: um estudo teórico a respeito do papel de centros formais e informais de capacitação de leitores e seu papel na (re)construção de emblemas identitários; uma etapa prática, com a realização de círculos de leitura literária e audiovisual e discussão temática com a comunidade; por fim, na última fase, pretendeu-se a análise dos resultados da etapa prática e redação do texto a ser utilizado como material pedagógico que aponte para os resultados da pesquisa, discutindo a importância das bibliotecas comunitárias para o fortalecimento de ações educacionais e de cidadania, na medida em que se constituem como espaços de discussão e construção de saberes e memórias.

Ao longo de um ano de pesquisa, entre abril de 2014 e maio de 2015, essa proposta sofreu significativa transformação pois, no ensejo das comemorações de dez anos de oficialização da Biblioteca Comunitária Maria das Neves Prado como OSCIP (Organização da Sociedade Civil de Interesse Público), as ações previstas para um projeto de pesquisa individual ampliaram-se em atitude coletiva que culminou no I Encontro sobre livro, leitura e inclusão social no território Nordeste II da Bahia.

\section{Encontro sobre livro, leitura e inclusão social do território Nordeste II da Bahia}

A primeira edição do Encontro sobre livro, leitura e inclusão social no território Nordeste II da Bahia ocorreu de 4 a 7 de dezembro de 2014 no povoado de São José do Paiaiá, organizado pela parceria entre a Universidade Estadual de Feira de Santana (através da Pró-Reitoria de Extensão, do Programa de Pós-graduação em Educação e do Programa de Pós-graduação em Estudos Literários), a Universidade do Estado da Bahia (através do Departamento de Educação do Campus II e do Programa de Pós-graduação 
em Crítica Cultural), a Fundação Biblioteca Nacional e a Associação Comunitária Biblioteca Maria das Neves Prado.

Nas primeiras reuniões entre as instituições parceiras para rascunhar uma prévia de ações, o maior desafio era o de manter o caráter comunitário da biblioteca na programação. Era preciso discutir com as pessoas do povoado, usuárias e gestoras da biblioteca, quais seriam as atividades prioritárias. A proposta de unir saberes a partir de uma junção contra-hegemônica entre popular e erudito culminou, na primeira edição, na programação que incluiu palestras e mesas-coordenadas sobre o papel das bibliotecas como equipamentos de incentivo à leitura; os desafios da educação no campo; leitura e formação de leitores; leituras literárias, digitais e cinematográficas e experiências de leitura, tendo como ponto máximo a palestra "Uma vida com a ficção", ministrada pelo escritor, membro da Academia Brasileira de Letras e sertanejo do Junco (pertinho do Paiaiá), Antônio Torres. Além das atividades acadêmicas, o evento proporcionou à comunidade a participação em minicursos e oficinas de leitura e criação literária, produção de brinquedos artesanais, confecção de bonecas de tecido, contação de histórias e educação para as relações étnico-raciais.

A parceria entre as universidades permitiu a ampliação das Comissão Científica e Organizadora e viabilizou recursos em passagens, materiais de apoio e diárias de alguns pesquisadores. Além disso, a produção de um evento com tamanha variedade de participantes, de várias partes do país, foi possível graças a recurso financeiro recebido através de edital do Programa de Apoio a Eventos no País (PAEP) da CAPES. Graças a este financiamento foi possível lançar, em 2016, a coletânea de artigos e ensaios resultantes das atividades do evento, intitulada Livro, leitura e inclusão social no sertão baiano (NOVAES et al, 2016).

$\mathrm{Na}$ apresentação do livro, a professora emérita da Faculdade de Filosofia, Letras e Ciências Humanas da USP - e madrinha da Biblioteca do Paiaiá - Walnice Nogueira Galvão, ressalta a responsabilidade da biblioteca nos processos de formação e democratização do saber, ao afirmar que, com o Encontro sobre livro, leitura e inclusão social no Território Nordeste II da Bahia,

Confirma-se a vocação da Biblioteca do Paiaiá como foco irradiador do enriquecimento cultural, de pensamento progressista, de desenvolvimento humano, de consciência cidadã e de preocupação com o saber e sua transmissão, seja nas ciências, seja nas artes (GALVÃO In NOVAES et al, 2016, p. 14).

As palavras de Walnice Nogueira Galvão são também um chamamento para a continuação do projeto do Encontro, a despeito da conjuntura política e financeira menos favorável a partir de 2015. Após a primeira edição, foi feita uma breve avaliação do evento e as comissões organizadora e científica pactuaram que novas edições seriam realizadas, em caráter bienal.

O II Encontro sobre livro, leitura e inclusão social no Território Nordeste II da Bahia aconteceu de 3 a 5 de novembro de 2016, com recursos financeiros quase exclusivos da Comissão organizadora, ainda composta por UEFS, UNEB, Associação Biblioteca Comunitária Maria das Neves Prado, com o acréscimo da UNILAB. Sem apoio político ou financeiro, as atividades acadêmicas e artístico-culturais foram ofertadas em menor quantidade, mas privilegiando a qualidade. Mais uma vez o engajamento da comunidade de São José do Paiaiá foi fundamental para a realização do evento. Os moradores do povoado abriram suas casas para abrigar e alimentar os palestrantes 
convidados, já que não havia recursos para pagamento de diárias. Os convidados, em sua maioria, custearam seu traslado de outras cidades/estados para garantir sua participação.

O caráter de biblioteca comunitária, que atua sem dependência de governos, por vontade e ação da comunidade, permitiu que a programação, como na primeira edição de 2014, contasse com palestras e mini-cursos, oficinas e mesas-coordenadas. As identidades culturais definidas na demarcação do território são também alvo de discussão da biblioteca e os eventos têm sido espaço de questionamento, problematização, mas também de afirmação de características regionais. Por isso, a abertura das atividades foi feita pelo professor doutor João Carlos Barreto, ex-reitor da UEFS, com a palestra "Leituras d'Os Sertões de Euclides da Cunha".

Além da abertura, os temas variaram entre a importância das bibliotecas para a formação de leitores, os diálogos entre literatura e cinema a partir de textos de cordel, outros letramentos cotidianos - saberes da vida e saberes das letras, literatura moçambicana e apresentação de contos. Dentre as palestras, causaram comoção a fala da professora Heleusa Câmara, da Universidade Estadual do Sudoeste da Bahia e coordenadora do PROLER, intitulada "Entre tantas leituras, as que não devo esquecer" e a apresentação do jornalista Marcelo Torres, “Como o sertão me tornou um leitor". Nessas duas palestras, como na de abertura, os convidados ressaltaram como movimentos leigos e tradicionais de leitura como a contação de histórias e causos, a declamação de poemas retirados do cordel e o hábito da leitura em voz alta, para além do letramento escolar, são fundamentais para a formação do gosto pela leitura e da consciência cidadã.

Apesar de não haver recursos materiais de origem governamental, nesta edição houve uma colaboração valiosa advinda dos municípios de Nova Soure e Olindina: a presença de representantes das Secretarias Municipais de Educação, na mesa coordenada "A gestão escolar e os desafios da formação de leitores na educação básica". Em suas falas, as gestoras apresentaram os indicadores de proficiência, alfabetização e evasão escolar. Dentre as escolas da região, a Escola Municipal São José do Paiaiá se destaca pelos indicadores positivos, atribuídos à presença-ação da biblioteca no povoado, o que fortalece o entendimento de que a biblioteca comunitária é também um equipamento de transformação social. A biblioteca estabelece com a escola uma relação de troca que supera o fetiche pelo livro como objeto cultural - produto de mercado. Como afirma Geraldo Prado, a biblioteca comunitária é um território de memória, que promove transformação através de ações pragmáticas de letramento e de ações simbólicas e afetivas de identificação. Segundo o autor:

A transferência da informação não existe sem estar no centro das ações dos sujeitos sociais, que certamente manifestarão as suas emoções no processo da construção e da transmissão do conhecimento sobre os mais diferentes fenômenos do seu cotidiano, e não simplesmente sobre o domínio de uma ferramenta tecnológica, embora isto também seja importante (PRADO, 2010, p. 148).

Seguindo essa reflexão, a defesa de instâncias produtoras e disseminadoras de conhecimento passa pelo enfrentamento de obstáculos, como a escassez de recursos materiais e de apoio de entes públicos. Ao fazer a avaliação da segunda edição do Encontro, a comissão organizadora percebeu que a coincidência com anos eleitorais é fator prejudicial para a captação de apoio político: alguns ofertam auxílio e capitalizam sua participação em campanha; outros recusam apoio, por divergência ideológica com participantes da organização. Tanto em um caso como no outro o resultado compromete a autonomia do evento. 
Em coerência com essa avaliação, a terceira edição do Encontro sobre Livro, Leitura e Inclusão Social no Território Nordeste II da Bahia aconteceu de 03 a 05 de agosto de 2017, com um desafio a mais: ser organizado com menos de um ano de intervalo da edição anterior. Mas a Biblioteca do Paiaiá atrai pessoas, e além das Universidades que já atuavam como parceiras, o III Encontro contou com a inclusão da Universidade Federal de Sergipe no grupo de instituições apoiadoras/realizadoras.

Em três dias foram oferecidos mini-cursos e oficinas diversos, desde os já tradicionais, de leitura literária e cinematográfica, até novidades como criação de quadrinhos, teatro e produção de fanzines. A tecnologia, inclusive, foi uma aliada importante, porque graças a isso foi possível garantir a palestra da professora Lídia Freitas, da Universidade Federal Fluminense, intitulada "A mediação de leitura em sala de aula", via videoconferência. Mais uma vez os participantes, de vários estados e instituições, compareceram com recursos próprios, por engajamento com a causa da educação e da democratização do saber, e assim houve representação, entre outras instituições locais, do Museu do Índio (RJ), Instituto Brasileiro de Ciência e Tecnologia (IBICT-RJ), Universidade Federal de Sergipe (SE), Universidade Estadual de Feira de Santana (BA), Universidade do Estado da Bahia (BA), Universidade da Integração Internacional da Lusofonia Afro-brasileira (CE-BA) e Sociedade dos Observadores de Saci (SP).

Com relação à Sociedade dos Observadores de Saci - SOSACI, cabe destacar a palestra "A linguagem das histórias infantis no folclore brasileiro", do professor Mouzar Benedito da Silva, coordenador da SOSACI. Em sua fala, que encerrou as atividades acadêmicas, a união entre letramento formal e informal, folclore a literatura, trouxe à cena da discussão a relevância de ações e estratégias de fomento à leitura que valorizem o contemporâneo e o tradicional, o popular e o erudito, na construção de movimentos de formação afetivos, técnicos e cidadãos ao mesmo tempo.

\section{Projeto Experiências de Leitura em Literatura e Cinema na "Maior Biblioteca Comunitária Rural do Mundo"}

A despeito das dificuldades orçamentárias enfrentadas pelas instituições desde outubro de 2016, quando a mudança de governo apontou para um maior arrocho nos recursos para educação e cultura (incluindo a extinção e posterior restabelecimento sucateado - do Ministério da Cultura), algumas políticas públicas, de caráter local, foram mantidas. Uma delas foi o Edital Setorial de Leitura, da Secretaria de Cultura do Estado da Bahia, financiado com o Fundo de Cultura do Estado da Bahia. O edital, lançado em 2016, previu o patrocínio de ações a serem desenvolvidas no ano de 2017, e foi uma oportunidade de ampliar as ações da Biblioteca do Paiaiá.

Coordenado pela professora Mírian Sumica Carneiro Reis, da UNILAB - Malês, o projeto "Experiências de leitura em literatura e cinema na "maior biblioteca comunitária rural do mundo"", contemplado no referido edital, propôs-se a incentivar a formação de leitores e mediadores de leitura a partir da seleção, treinamento e remuneração de jovens da comunidade de São José do Paiaiá. As ações foram desenvolvidas nas seguintes etapas:

\section{Processo seletivo de monitores/as para atuar como mediadores/as de leitura:}

Em fevereiro de 2017, lideranças entre os jovens da comunidade de São José do Paiaiá foram convidadas a colaborar na divulgação e incentivo à participação no processo de seleção para atuar como mediadores de leitura. A resposta foi muito positiva e 17 jovens, de 14 a 21 anos, participaram da prova de redação em que deveria ser respondida 
a seguinte pergunta: "Na sua opinião, como a leitura pode contribuir para a formação de cidadãos conscientes?"

Dos dezessete inscritos, doze foram selecionados. Seis atuaram no primeiro semestre de 2017 e os outros seis no segundo, respeitando assim o orçamento aprovado pelo Fundo de Cultura da Bahia, que autorizou pagamento mensal de $\mathrm{R} \$ 200,00$ como bolsa para cada monitor.

As redações foram corrigidas por Mírian Sumica Carneiro Reis, professora da Universidade da Integração Internacional da Lusofonia Afro-brasileira, e pelo professor Claudio Cledson Novaes, da Universidade Estadual de Feira de Santana, como pareceristas cegos, já que os textos não foram assinados, apenas numerados. Após divulgação do resultado, iniciou-se o trabalho de orientação dos monitores e definição dos seus planos de ação.

\section{Treinamento dos/as mediadores/as de leitura}

Após divulgação dos resultados, os jovens selecionados para atuar como mediadores/as de leitura passaram por um período de treinamento, que contou com o apoio de José Arivaldo Prado (presidente da Associação Biblioteca Comunitária Maria das Neves Prado) e Francisco dos Santos (voluntário apoiador da biblioteca). Neste momento, os bolsistas foram apresentados ao acervo, sua classificação e acessos. Aprenderam, nas reuniões de orientação com a coordenação do projeto, a apresentar propostas de leitura conforme o público do momento, precisando, para isso, serem eles mesmos leitores de obras variadas, a fim de que pudessem fazer indicações de leitura. Os jovens foram o tempo inteiro estimulados a propor ações de leitura formal e informal, em parceria como a Escola Municipal São José do Paiaiá, de modo a manter a relação de intercâmbio de saberes e formação comunitária.

\section{Sessões de leitura cinematográfica}

Como previsto no projeto aprovado pela Secretaria de Cultura, as sessões de leitura cinematográfica foram iniciadas a partir da exibição, seguida de discussão, de filmes nacionais. A primeira exibição ocorreu no dia 03/03/2017, com recepção muito positiva da comunidade pois, além de estimular o hábito e o gosto pela leitura audiovisual, as sessões de leitura cinematográfica se configuram também como alternativa de lazer cultural na comunidade tão carente deste tipo de atrativos.

Inicialmente, a meta de público previa maioria de adultos, considerando-se os títulos das obras escolhidas. Contudo, a participação de crianças e adolescentes superou as expectativas. A cada sessão o público variou entre quarenta e sessenta pessoas, dentre as quais apenas o quantitativo aproximado de quinze adultos se fez presente. Nas primeiras sessões, as crianças faziam grande algazarra, na expectativa pela hora do lanche, mas, ao longo das sessões, foi possível notar um amadurecimento daquele público, que já esperava acomodado pelo filme do dia. Com as crianças da comunidade, o projeto superou sua proposta inicial de formação de leitores: garantiu acesso a formas variadas de leitura, em outros suportes, para públicos de idade e condição social também diversas.

Da primeira sessão em março até a última em dezembro de 2017, foram realizados vinte e um círculos de leitura cinematográfica, que seguiram a seguinte programação, divulgada na comunidade e nas redes sociais através do cartaz abaixo: 
Figura 1: Cartaz Calendário de sessões cinematográfica

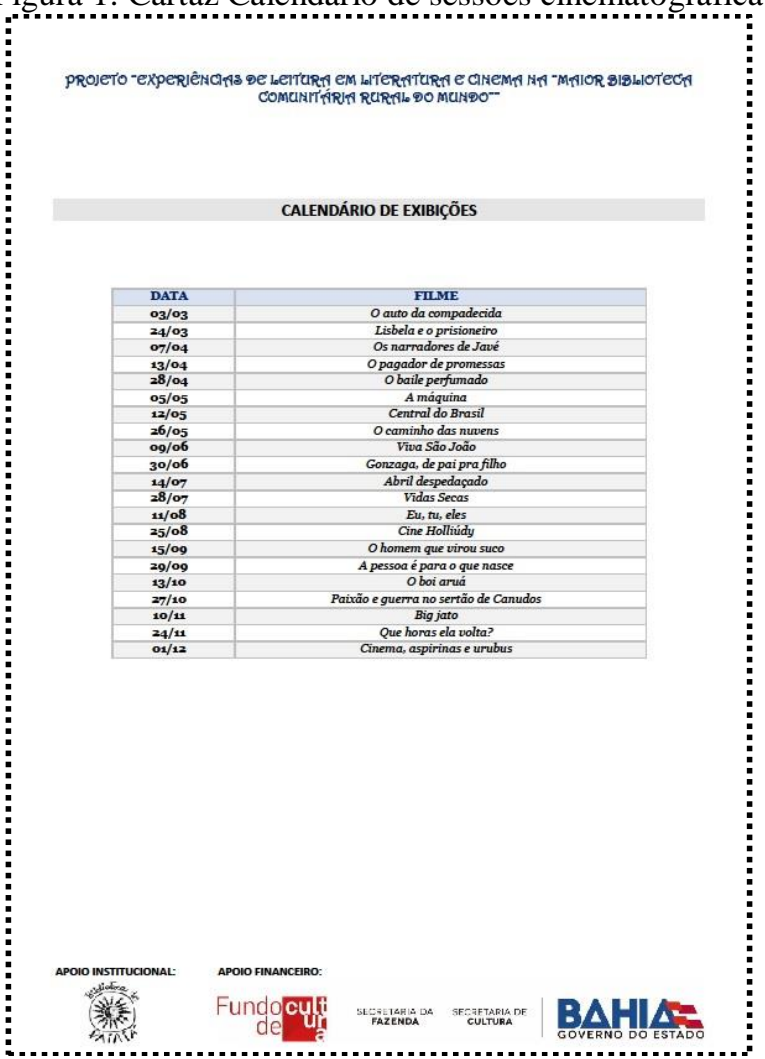

Acervo: Biblioteca do Paiaiá

Figura 2: Sessão de exibição

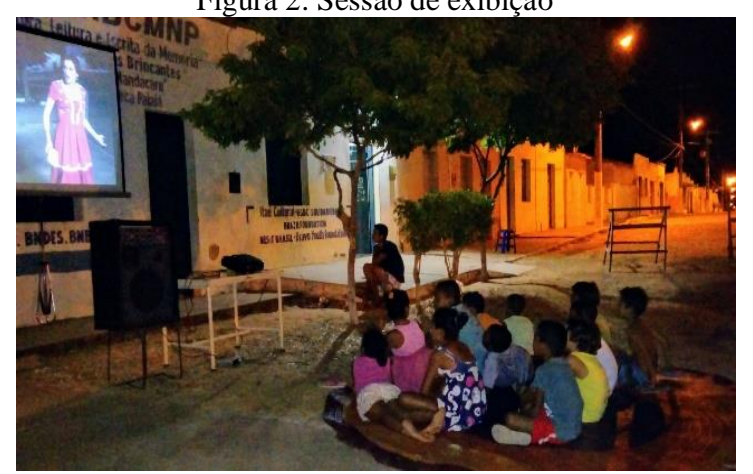

Fonte: Acervo pessoal

Figura 4: Círculo de leitura na Biblioteca

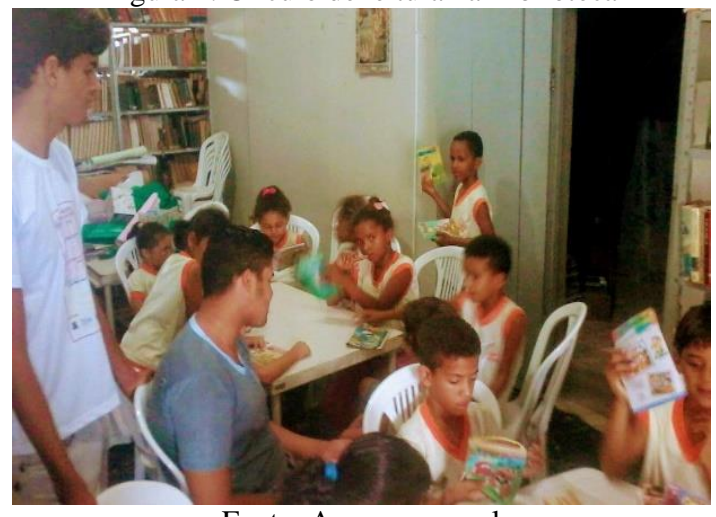

Fonte: Acervo pessoal

* Criação dos bolsistas mediadores de leitura.
Figura 3: Crianças assistindo o filme

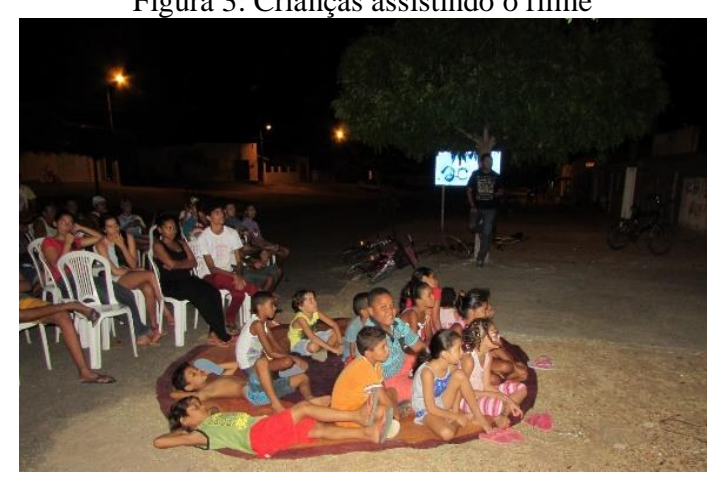

Fonte: Acervo pessoal

Figura 5: Identidade visual do projeto*

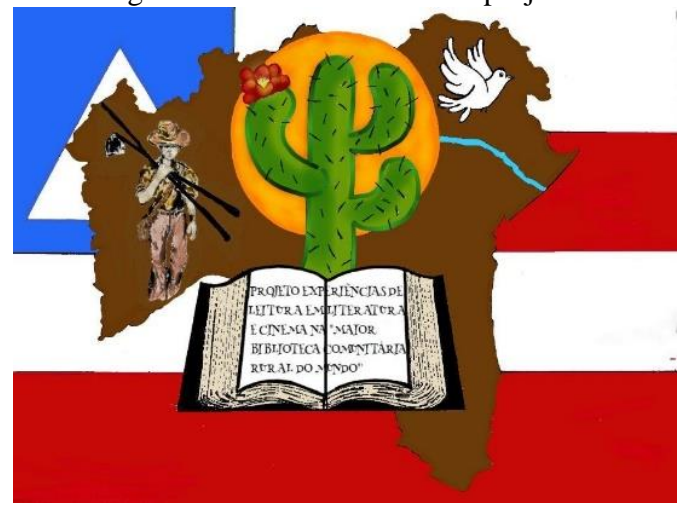

Fonte: Acervo pessoal 


\section{Sonho que se sonha junto...}

No artigo "A formação de leitores no cenário atual: desafios e responsabilidades" (LIMA; BESNOSIK In NOVAES et al, 2016), Rita de Cássia Lima e Maria Helena Besnosik apontam, a partir da análise de pesquisas contemporâneas sobre leitura e letramento, para o desafio de conciliar a ampliação do conceito de leitura com as novas e avanços possibilidades de acesso a partir da tecnologia. Leitura literária, técnica, artística, leitura de vida e de mundo... esses conceitos promovem uma mudança na ideia de que a leitura é o exercício solitário entre um sujeito e seu objeto - o livro - e passam a considerar o caráter coletivo das ações de leitura. Para as autoras,

Com todos os avanços (sociais, políticos, culturais, tecnológicos etc) que a sociedade atingiu, e não são poucos, infelizmente ainda não conseguimos resolver o problema da falta de acesso de parte significativa da população aos bens culturais e ao exercício efetivo das práticas socioculturais da leitura. Sendo assim, os desafios na atualidade para a formação de leitores críticos, competentes e proficientes vão para além da forte influência dos aparelhos celulares e das demais mídias eletrônicas. Estes trazem, sem dúvida, uma necessidade emergente de envidarmos esforços no sentido de compreendermos e buscarmos saídas competentes para lidarmos com a invasão, sem limites, do uso exacerbado dos equipamentos tecnológicos. Mas os desafios perpassam também pela necessidade urgente de reconceituarmos e redefinirmos a concepção de leitor e leitura (LIMA; BESNOSIK In NOVAES et al, 2016, p. 268 269).

Redefinir, re-conceituar, ampliar as acepções sobre leitor e leitura propõem uma abertura para novos olhares sobre as práticas de letramento e compreensão da dimensão dos desafios impostos aos espaços tradicionais de formação. Os manuais tornam-se obsoletos, porque ainda desconsideram a realidade contemporânea da velocidade de acesso à informação. Se esta informação, promovida com os filtros das redes sociais e das grandes plataformas como o Google, é qualificada, é um outro aspecto a ser analisado, mas não se pode desconsiderar esta realidade, nem pensar a as práticas de letramento a partir da ótica nostálgica de que "os jovens não leem".

Como tornar uma biblioteca, e seu acervo de mais de cem mil títulos, em um equipamento dinâmico de fomento à leitura, num contexto de preferência pelo acesso digital à informação?

Esta pergunta tem sido ao mesmo tempo o desafio e o estímulo de quem acredita no papel da biblioteca comunitária como agente trans-formador. Mesmo quando o espaço está fechado, há um número de frequentadores sempre presente sob o pé de pau-brasil que fica na entrada da Biblioteca do Paiaiá, para aproveitar o sinal aberto e gratuito de wi-fi. As pessoas do povoado, mesmo com a dificuldade de sinal telefônico, estão conectadas com o mundo e essa também é uma ação de inclusão promovida pela biblioteca.

Com os projetos, financiados ou não, a procura por aquele espaço não se restringe ao lado externo. As crianças aproveitam o recreio lendo as revistas em quadrinhos, a escola discute filmes exibidos na sala de projeção, pesquisadores de vários lugares acessam o acervo e visitantes se encantam com o milagre que é manter um sonho de inclusão social por meio da leitura, mesmo com tantas adversidades, num território ainda tão carente. 
A Associação Biblioteca Comunitária Maria das Neves Prado - a Biblioteca do Paiaiá - é um símbolo de resistência, que prova que o tecnológico não concorre com o tradicional, porque eles são suplementares. Aquele espaço, "oásis no sertão", como alcunhou um visitante entusiasta certa vez, cumpre um papel maior, o de referência e marca identitária, no sentido proposto por Michele Petit, ao refletir sobre a permanência e re-existência das bibliotecas em tempos de inovação e tecnologia:

La biblioteca es una de las instituiciones más generosas que hayan inventado los seres humanos - a condición de no encontrarla con la puerta cerrada a toda hora y a condición de atreverse a entrar em ella, lo que frecuentemente supone que algunos bibliotecários hayan salido de ella -. Es uno de los pocos lugares que escapan, al menos hasta hoy, a la lógica exclusiva del lucro. Da prueba de una continuidade, es como um punto de referencia estable que puede proveer un sentimiento de pertenencia muy danãdo em tempos de crisis. "Es como una presencia, la biblioteca", me dijo una mujer, em el suburbio parisino. Estamos mucho más allá de un simple banco de informaciones manejado por técnicos (PETIT, 2016, p. 196).

Mais do que o espaço privilegiado de leitura, a Associação Biblioteca Comunitária Maria das Neves Prado se consolida como território de memória que inscreve o pequeno povoado de São José do Paiaiá numa cartografia política e cultural que habitualmente se concentra nos grandes centros urbanos. Como nas palavras de Petit, ela se tornou uma referência, uma presença que instaura novas possibilidades de produção e difusão de saberes. Não é a única, felizmente, mas é pioneira na subversão do processo de busca pelo conhecimento: a academia sai do centro e penetra o sertão, nos Encontros sobre livro, leitura e inclusão social.

O projeto "Experiências de Leitura em Literatura e Cinema na "Maior Biblioteca Comunitária Rural do Mundo"' promoveu a formação de público leitor de literatura e cinema e, através das bolsas para os mediadores, promoveu também apoio financeiro para jovens carentes. Políticas públicas e iniciativas comunitárias, juntas, ampliam os resultados do trabalho por inclusão social a partir dos letramentos e da educação.

O sonho de Geraldo Prado, de Ari, de Francisco, é também o sonho de Mírian, Cláudio, Malena, Rita, Alana, Maria Antônia, Jaqueline, Matteus, Caio, Leidiane, Bruna, Sidnei, Renata, Evani, Antônio, Frederico, Maria Elis e tantas outras pessoas que acreditam no papel emancipador da leitura através de práticas comunitárias, engajadas e inclusivas, que reinventam identidades e tiram o sertão e o sertanejo do lugar fixado de exclusão para o de produtor de inovação e conhecimento. 


\section{REFERÊNCIAS}

CANDIDO, Antonio. O direito à literatura (1988). In: CANDIDO, Antonio. Vários escritos. 4. ed. São Paulo / Rio de Janeiro: Duas Cidades / Ouro sobre azul, 2004, p. 169191.

GALVÃO, Walnice Nogueira. Apresentação. In: NOVAES, Claudio Cledson et al (orgs.). Livro, leitura e inclusão social no sertão baiano. Feira de Santana: UEFS Editora, 2016, p. 11-15.

LIMA, Rita de Cássia Brêda M.; BESNOSIK, Maria Helena da Rocha. A formação de leitores no cenário atual: desafios e responsabilidades. In: NOVAES, Claudio Cledson et al (orgs.). Livro, leitura e inclusão social no sertão baiano. Feira de Santana: UEFS Editora, 2016, p. 263-280.

MACHADO, Elisa Campos. Uma discussão acerca do conceito de biblioteca comunitária. Revista Digital de Biblioteconomia e Ciência da Informação, v. 7, n. 2, 2009. https://periodicos.sbu.unicamp.br/ojs/index.php/rdbci/article/view/1976/2097. Vários acessos.

PETIT, Michèle. Leer el mundo - experiencias actuales de transmisión cultural. Traducción de Vera Waksman. 2. Reimp. Ciudad Autónoma de Buenos Aires: Fondo de Cultura Económica, 2016 (Espacios para la Lectura).

PRADO, Geraldo Moreira. A biblioteca comunitária como agente de inclusão/ integração do cidadão na sociedade da informação. Revista Inclusão Social, IBICT, Brasília, DF, v. 3, n. 2, p.143-149, jan./jun., 2010. Disponível em: http://revista.ibict.br/inclusao/article/view/1638/1844. Vários acessos.

REIS, Mírian Sumica Carneiro. Leitura de cinema no currículo do ensino básico: a lei 13006/2014. In: NOVAES, Claudio Cledson et al (orgs.). Livro, leitura e inclusão social no sertão baiano. Feira de Santana: UEFS Editora, 2016, p. 209- 236. 